\title{
Experimental Investigation of Unsteady Pressure on an Axial Compressor Rotor Blade Surface
}

\author{
Qingwei Wang, Bo Liu, Xiaorong Xiang, Xiangfeng Bo, Weimin Hou \\ School of Engine and Energy, Northwestern Polytechnical University, Xi'an, China \\ E-mail:wqw@mail.nwpu.edu.cn \\ Received March 16, 2010; revised April 21, 2010; accepted May 15, 2010
}

\begin{abstract}
The inherent unsteady pressure fluctuations on the rotating blade suction surface of an axial compressor were experimentally measured by directly mounting five high response miniature pressure transducers into the rotor blade along a streamline at 50\% span respectively. The results show that the unsteady pressure fluctuations of rotor blade surface could be measured successfully by this means. The relations about the period, altitude of unsteady pressure with rotating speed, the discipline of pressure fluctuation along the streamwise direction were obtained.
\end{abstract}

Keywords: Kulite Transducer, Rotating Blade, Unsteady Pressure, Experimental Measurement

\section{Introduction}

It is well known that the flow fields in turbomachinery is inherently unsteady because of the aerodynamic blade row interaction, the viscous flows, secondary flows, tip clearance flows and so on. The efficiency of turbomachine blades and the overall performance of the machine strongly depend on the unsteady flow. Furthermore, the unsteady flow substantially influences blade forces and the high-cycle fatigue of blades. Therefore the research about unsteady pressure on blade surface, especially the rotor blade surface, is very necessary. During the past decades, an increasing experimental investigation of the unsteady pressure fluctuation on rotating blade surface have been carried out by directly embedding the high response miniature pressure transducers in rotor blades and got great successes [1-6].

In this paper, five high response miniature pressure transducers were directly mounted in the rotating blade of an axial compressor along a streamline at $50 \%$ span, to measure the unsteady pressure fluctuations on the rotor blade suction surface. During experiment, the data logger was fixed and rotated with the compressor axletree, which could directly sample, amplify and store the pressure signals.

\section{Experimental Facilities}

\subsection{Axial Compressor Test Rig}

The experimental study was conducted in a single stage axial compressor test rig at the Northwestern Polytechnical University, which consisted of 20 rotating blades and 23 stationary vanes, and work at the rotating speed from 0 to $3000 \mathrm{r} / \mathrm{min}$. Figure 1 shows the scheme of the axial compressor. Some the geometric data were: the tip radius was $290 \mathrm{~mm}$, the hub radius was $174 \mathrm{~mm}$, and the rotor blade tip clearance size was $1.0 \mathrm{~mm}$. Design parameters of the compressor: design speed was $3000 \mathrm{r} / \mathrm{min}$, mass flow was $5.97 \mathrm{~kg} / \mathrm{s}$, total pressure rise was $1870 \mathrm{~Pa}$, and isentropic efficiency was 0.875 . The compressor was driven by an AC motor (15 KW). The area of outlet was controlled by moving a throttle cone sited downstream of the test rig.

\subsection{Pressure Transducer}

Kulite model LQ-062 high response miniature pressure transducers were used in this study, as shown in Figure 2. The range of the transducer was \pm 5PSI, sensitivity was $18.318 \mathrm{mV} / \mathrm{PSI}$, and response frequency was $150 \mathrm{KHz}$. The pressure range of blade surface was about $\pm 0.5 \mathrm{PSI}$ relative to environmental pressure in this study, and the maximal response frequency of pressure fluctuations was low to $1000 \mathrm{~Hz}$, so the transducers could content the experiment requirements. In order to prevent breaking the transducers during installing or taking down, the transducers were stuck into the guard sheaths firstly, and then be mounted into the holes drilled through the rotor blade. The scheme of guard sheath is shown in Figure 3. In the front of the guard sheath there was a hole with the diameter $2 \mathrm{~mm}$ where the transducer was installed. The 


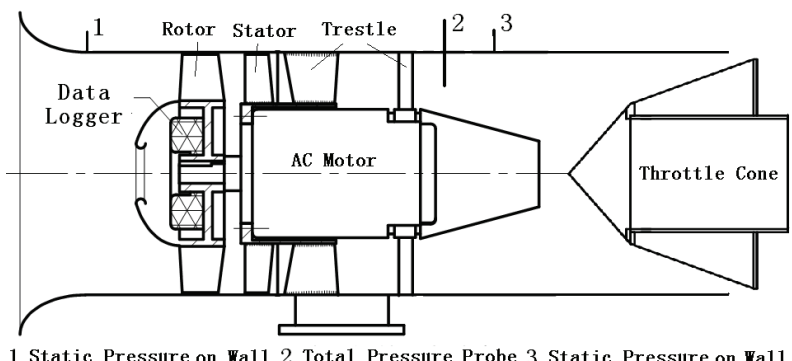

Figure 1. Axial compressor test rig.

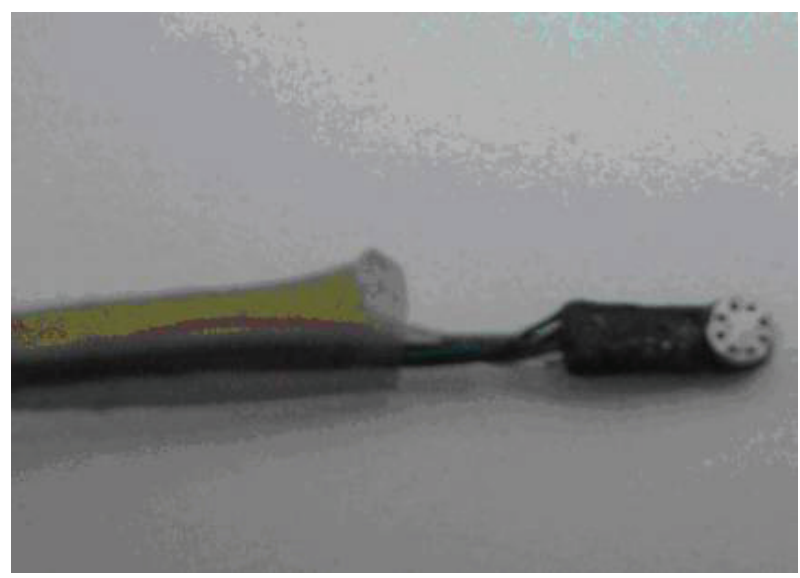

Figure 2. Kulite pressure transducer.

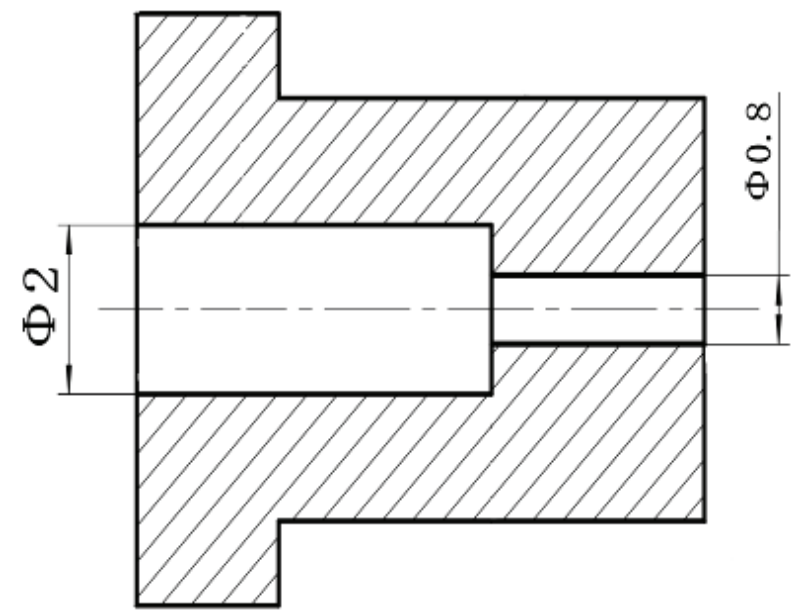

Figure 3. Guard sheath.

transducer sensed the pressure through a $0.8 \mathrm{~mm}$ diameter hole at another end of the guard sheath. The sketch of the transducer distributions is shown in Figure 4. Five transducers and guard sheaths were mounted at 5\%,20\%, $40 \%, 60 \%$, and $90 \%$ of axial chord position along the streamline at $50 \%$ span respectively. Just only five transducers were used in the investigation, to test and verify the experiment method and obtain some experiences. Next step, we will dispose more transducers on both the rotor suction and pressure surface, to obtain

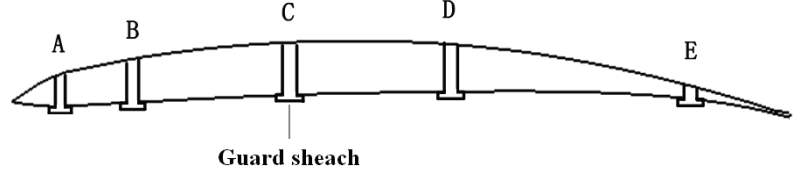

Figure 4. Distribution of pressure transducers.

more detailed unsteady pressure fluctuations on the rotor blade. The guard sheaths had some influence on flow fields of pressure surface side passage. However, the main purpose in this study was to measure the unsteady pressure on suction surface, and the suction surface configured a flow passage with the pressure surface of adjacent blade, so the effects of guard sheaths on the measurement flow fields were ignored.

\subsection{Data Acquisition System}

Figure 5 shows the data logger used in current study, which consisted of signal modulator, AD transform module, timer module, USB module and memorizer. The data logger had 8 channels and each channel sampled at the same time. The system sampling frequency was 100 $\mathrm{KHz}$, the amplifying multiple was 186 , and the memory capability was $1 \mathrm{G}$. The data would be continuously sampled for 10 minutes after the trigger infrared light aiming at the data logger. During experiment, the data logger was fixed and rotated with the drive shaft of the compressor as shown in Figure 6. The electrical wires of transducers were routed down along the blade pressure surface and through the hub to connect with the data logger, thus the data logger could supply powers for transducers. In additional, while the rotor was working, the data logger could directly amplified the electrical signals of transducers, and transform them to digital data, and then store to the memorizer. After the compressor stopping, the digital data stored in the memorizer was transferred to computer through a USB data line. Using the data logger could effectively avoid the distortion during data transmission and increased the data reliability.

\section{Experimental Results and Discussion}

In order to eliminate the electromagnetic interference of the AC motor, the shell of AC motor was connected with earth, and the electric wires of pressure transducers were shielded. In addition, the waves up $3000 \mathrm{~Hz}$ were sieved by software to reduce the effect of transducer noise signals, and that had little influence on the study. The interferences were weakened greatly by adopting the means above, which enhanced the reliability of pressure signals. The acquired dynamic pressure signals data consisted of time-average values and fluctuation values. For easy to analyze the unsteady pressure pulses, the time-average values was discarded from the gained signals data and 


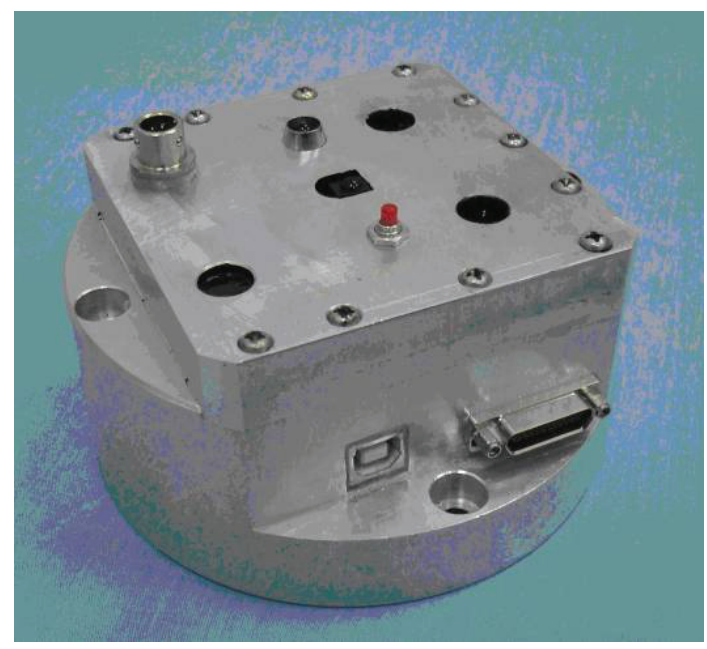

Figure 5. The data logger.

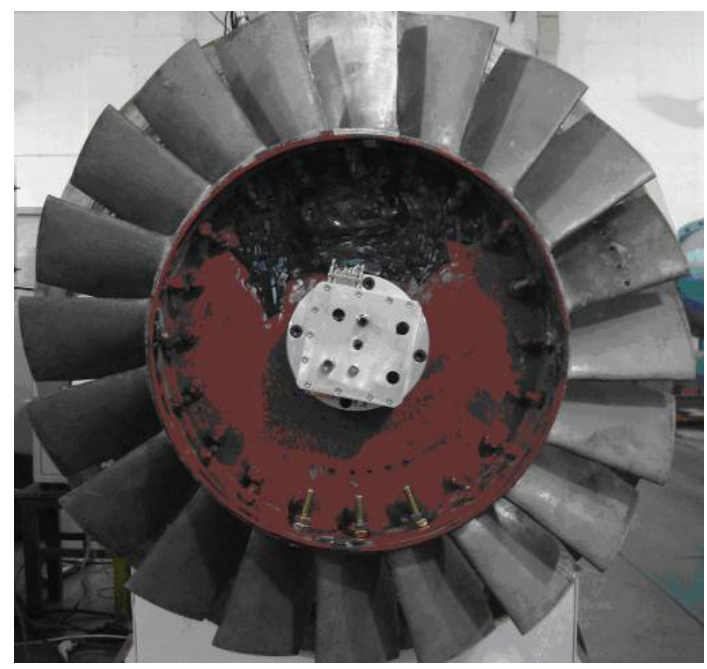

Figure 6. The fixing of data logger.

the fluctuation values was discussed only. The fluctuation values was defined using the following formula: $\tilde{p}=p-\bar{p}$. The $\tilde{p}$ was fluctuation value, the $p$ was dynamic pressure sampled and the $\bar{p}$ was the time-average value of the sampled pressure using the formula $\bar{P}=\left(\sum_{i=0}^{n-1} P_{i}\right) / n$. Before experiment, the whole acquisition system had been static calibrated precisely, that ensure the veracity of the measurement results.

The unsteady pressure measurement covered different speeds and an extensive range of mass flow. The investigation focus on the inherent unsteady pressure on rotor blade suction surface, so there was no any disturb source in front of the rotor. Figures 7-16 show the time-domain waves of 5 measurement points under $2000 \mathrm{r} / \mathrm{min}$ and $1000 \mathrm{r} / \mathrm{min}$ rotating speed while keeping the same outlet area. At the outlet area, the compressor was both near the peak value point of total pressure rise under $2000 \mathrm{r} / \mathrm{min}$ and $1000 \mathrm{r} / \mathrm{min}$ speed. From the figures it can be observed that the pressure fluctuations of rotor blade suction surface were periodical obviously. The period of waveforms at $2000 \mathrm{r} / \mathrm{min}$ speed was approximately 0.03 $\mathrm{s}$, and was about $0.06 \mathrm{~s}$ at $1000 \mathrm{r} / \mathrm{min}$ speed. All these periods were just the times that the compressor revolving one circle at each rotating speed, which shows that the frequency response of inherent unsteady pressure were related to rotating speed. It is obviously that the altitudes of unsteady fluctuations declined as the rotating speed down. The maximal altitude of fluctuation was about 300 $\mathrm{Pa}$ at $2500 \mathrm{r} / \mathrm{min}$ speed, which was about $85 \mathrm{~Pa}$ at 1000 $\mathrm{r} / \mathrm{min}$ speed. These show that the altitudes of the inherent pressure fluctuations were also related to the rotating speed. The periodical waveforms also contain some other complex pulses, which show the unsteady pressure fluctuations were very complicated. Because of the complication of unsteady flow fields, as well as the errors leading by the zero drift of transducers, each of the periodical waveforms is not absolutely the same with the other ones.

The reasons of blade surface unsteady pressure were various. The downstream stator was very far from the rotor. The axial distance between the rotor and stator was $268 \%$ of the rotor blade chord length at $50 \%$ span, so the stator gave little interaction to the flow fields of rotor blade passage. There were three main reasons of rotor blade surface unsteady pressure fluctuations. Firstly, although there were no any disturb source in front of the test rig, the flow fields of the blade passage was essentially unsteady because of the viscous flows, secondary flows, tip clearance flows and so on. Secondly, the inlet fairing of the compressor had a little warp and a bad concentricity, which resulted that the airflows passing by the inlet fairing and then flowing into the compressor were not absolutely uniform. Finally, there was a little vibration of test rig during experiment. As a result of fluid inherent characteristics, the inlet fairing and vibration of compressor, the pressure signals of the rotor blade surface were unsteady, and all the reasons were relate to the rotating speed, which were the reasons that the waveforms periods were approximately the same with the time compressor revolving one circle.

Figures 17-21 show the fairly typical time-domain waves and frequency spectral curves of 5 measurement transducers near peak value point of total pressure rise under $1500 \mathrm{r} / \mathrm{min}$ rotating speed. From the time-domain waves figures it can be observed that the waveforms periods of every measurement point were all approximately $0.04 \mathrm{~s}$, which was the time the compressor revolving one circle. From the frequency spectral curves, it also can be seen that the dominant frequency was the fundamental frequencies of $25 \mathrm{~Hz}$ and its hormonics, which was the compressor rotating frequency. All these further prove that the periods of waveforms were related to rotating speed. From the frequency spectral curves, it can be 


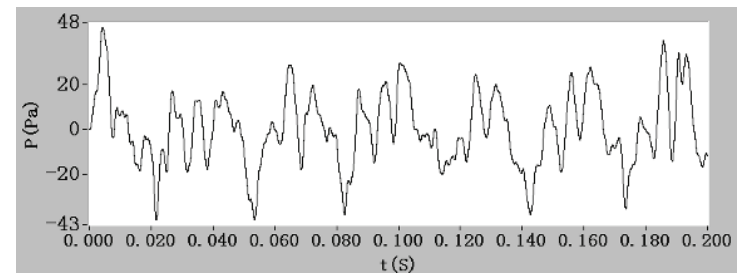

Figure 7. The time-domain waves of $A$ under $2000 \mathrm{r} / \mathrm{min}$.

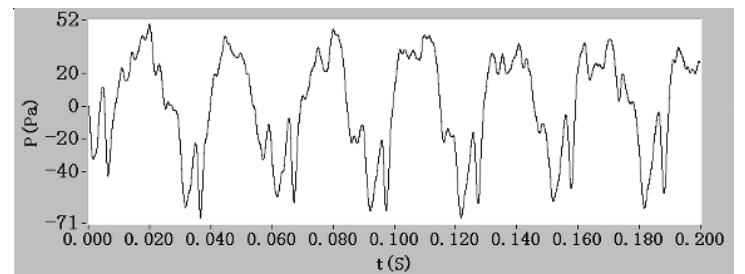

Figure 9. The time-domain waves of $B$ under $2000 \mathrm{r} / \mathrm{min}$.

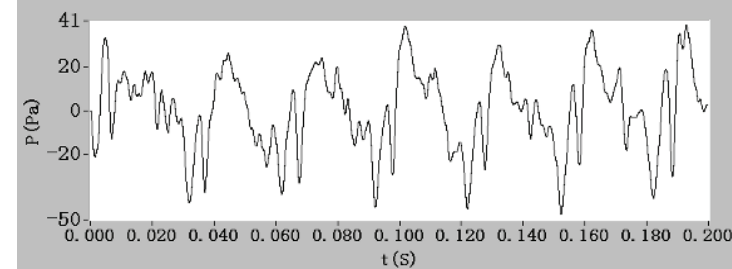

Figure 11. The time-domain waves of $C$ under 2000 r/min.

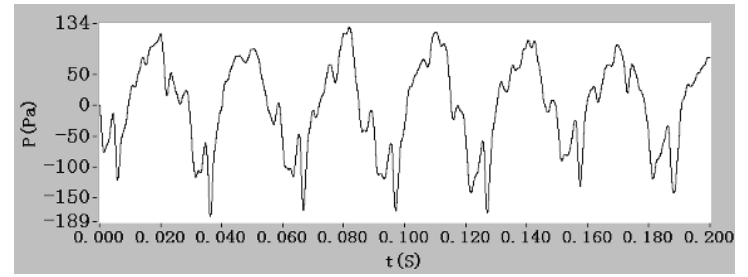

Figure 13. The time-domain waves of $D$ under $2000 \mathrm{r} / \mathrm{min}$.

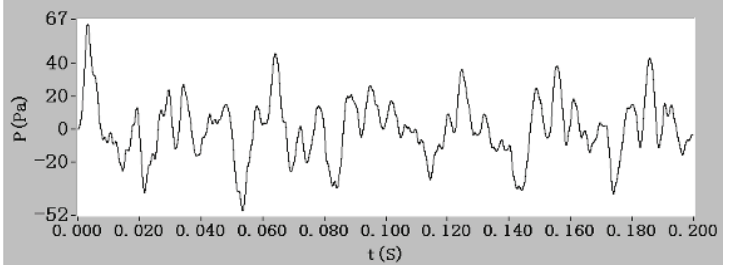

Figure 15. The time-domain waves of $E$ under $2000 \mathrm{r} / \mathrm{min}$.

seen that the peak values of the second, third, fourth and fifth order spectral were all remarkable at A point. From the relative Mach number contours at $50 \%$ span of the simulation as shown in Figure 22, it can be seen that the grads of the airflow velocity varied greatly near the blade leading edge, where the airflow began accelerating. Besides, the transducer at A point was located in the front of the blade, where the inlet no-uniform airflows had great influence. As a result of the two main reasons, the unsteady pressure fluctuation was complex at A point. Figure 23 represents the peak values of the first order

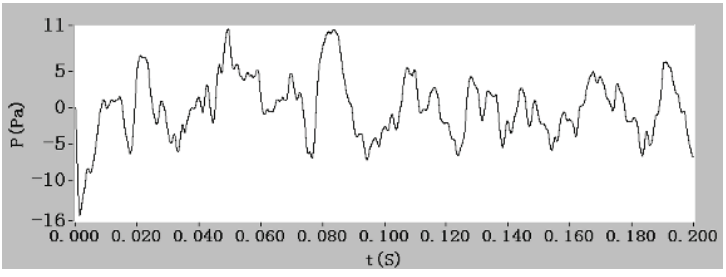

Figure 8. The time-domain waves of $A$ under $1000 \mathrm{r} / \mathrm{min}$.

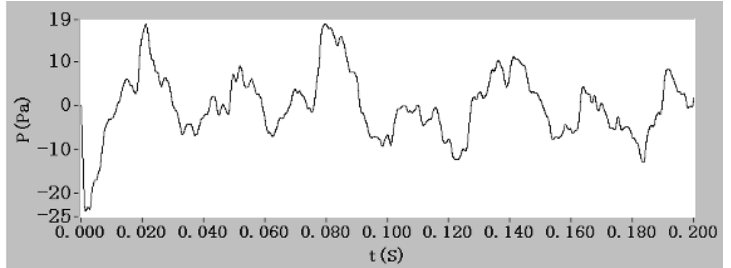

Figure 10. The time-domain waves of $B$ under $1000 \mathrm{r} / \mathrm{min}$.

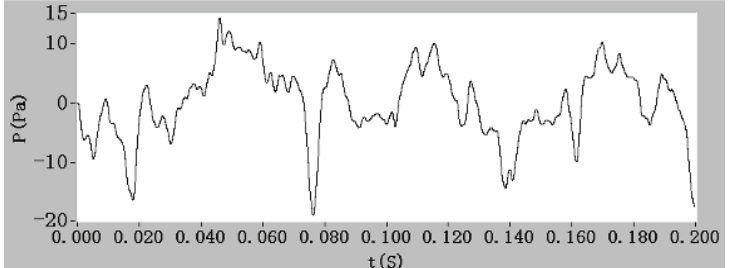

Figure 12. The time-domain waves of $C$ under $1000 \mathrm{r} / \mathrm{min}$.

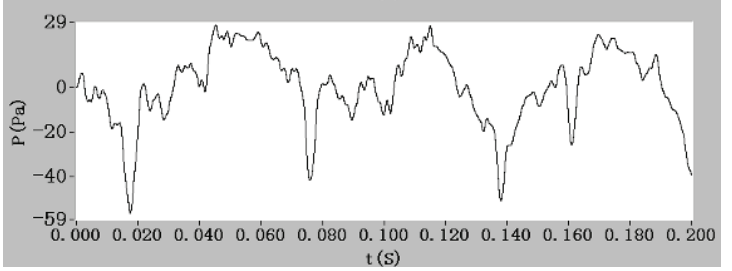

Figure 14. The time-domain waves of $D$ under $1000 \mathrm{r} / \mathrm{min}$.

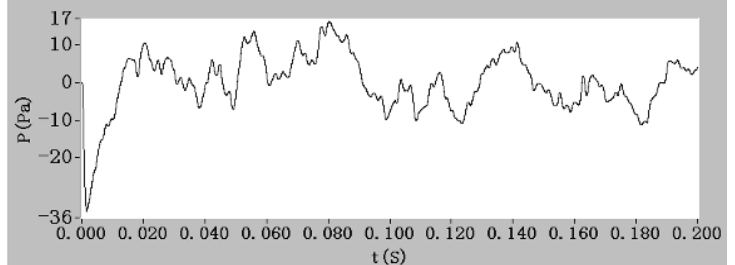

Figure 16. The time-domain waves of $E$ under $1000 \mathrm{r} / \mathrm{min}$.

spectral of every measurement point. It was obvious that the peak values of the first order spectral gradually increased from A to D point, and then declined at $\mathrm{E}$ point. Because the blade surface pressure gradually increased from blade leading edge to trailing edge, accordingly the altitude of pressure fluctuation increased from A to D point. From Figure 22 it can be seen that the boundary layers were thick near the blade trailing edge region, where the velocity and pulse of airflow were weak, so the boundary layers maybe the major contribution to the altitude of pressure fluctuation declining at $\mathrm{E}$ point. 


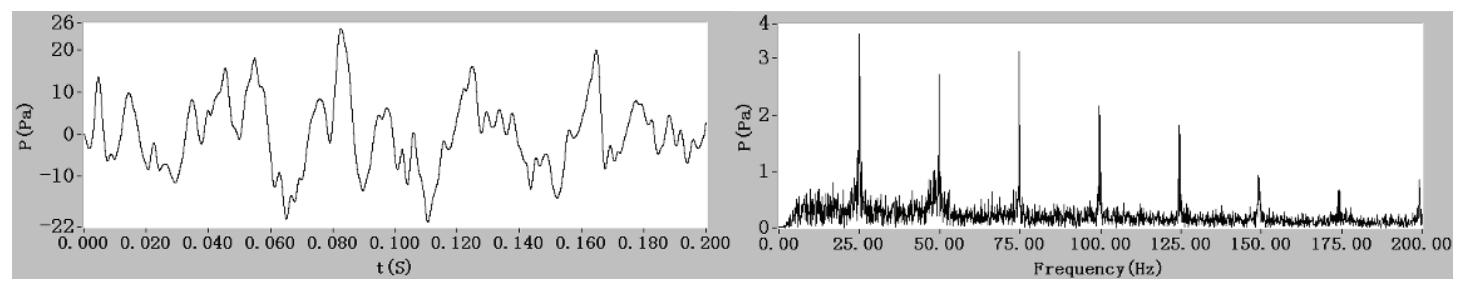

Figure 17. The time-domain waves and frequency spectral curves of $A$.

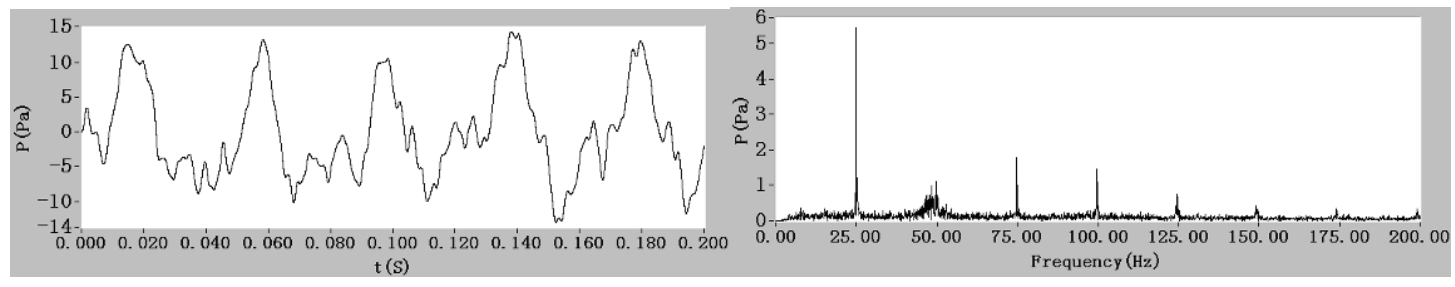

Figure 18. The time-domain waves and frequency spectral curves of $B$.

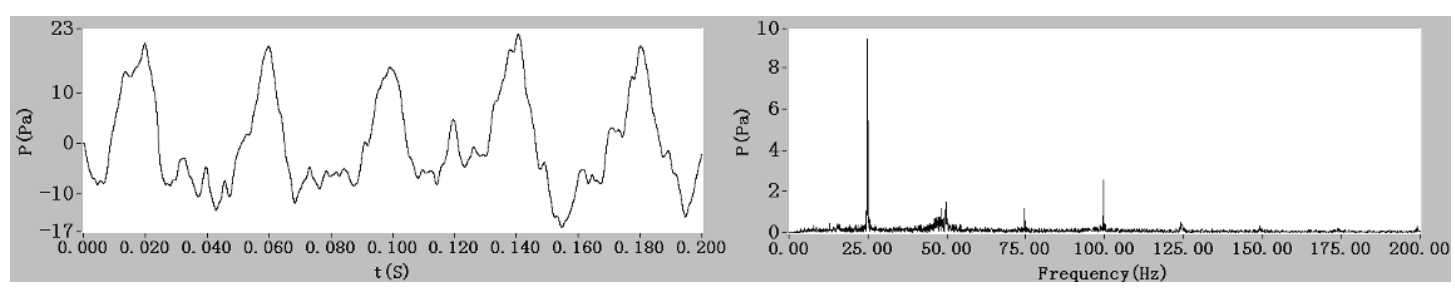

Figure 19. The time-domain waves and frequency spectral curves of $C$.

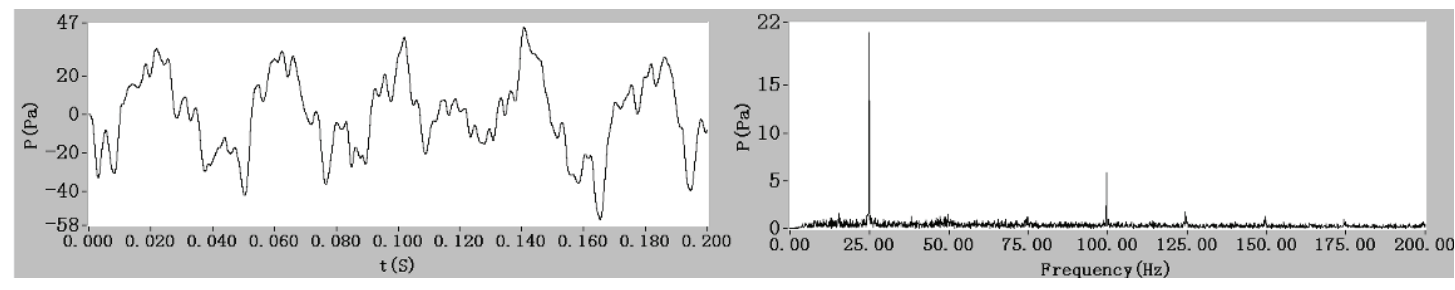

Figure 20. The time-domain waves and frequency spectral curves of $D$.

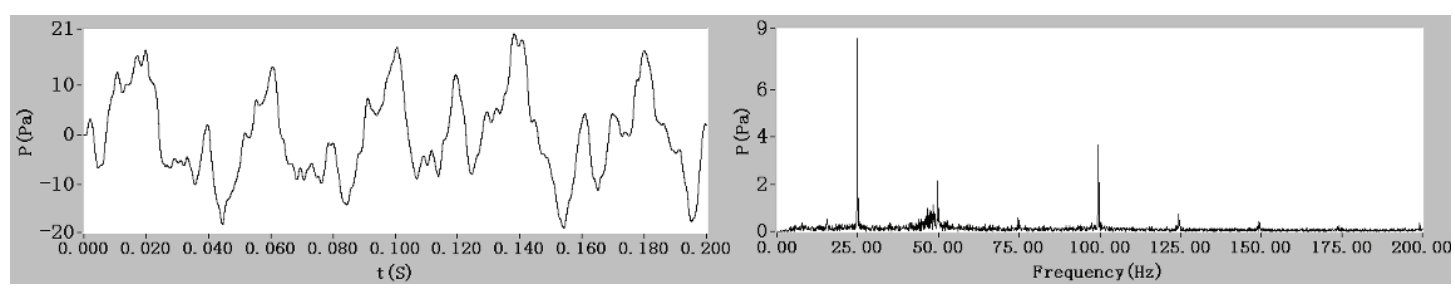

Figure 21. The time-domain waves and frequency spectral curves of $\mathbf{E}$.

\section{Conclusions}

The unsteady pressure on rotor blade suction surface were measured using five miniature pressure transducers, directly mounted in the rotating blade along a streamline at $50 \%$ span. The results show:

1) The unsteady pressure fluctuations of blade surface could be measured successfully by this means. The pressure fluctuations were periodical obviously, and the periods and the altitudes of unsteady fluctuations were all related to the compressor rotating speed.

2) The periods of waveforms were the same with the time of compressor revolving one circle; the fluctuations were weakened as the rotating speed down. 


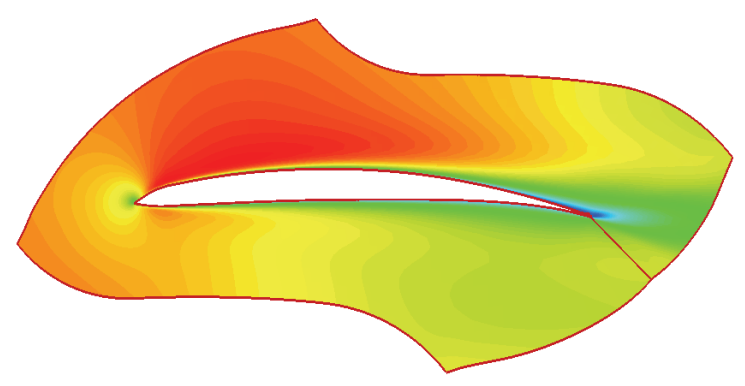

Figure 22. The relative mach number contours at $\mathbf{5 0 \%}$ span.

3) The pressure fluctuations gradually increased from leading edge to trailing edge. But owing to the boundary layers near the blade trailing edge region, the fluctuations declined.

\section{References}

[1] Y. F. Wang, J. Hu, B. N. Luo and C. P. Li, "Effects of the Upstream Blade Wakes on the Spectrum of Rotor Blade Unsteady Surface Pressure," Journal of Aerospace Power, Vol. 21, No. 4, 2006, pp. 693-699.

[2] T. Maeda and H. Kawabuchi, "Surface Pressure Measurement on a Rotating Blade of Field Horizontal Axis Wind Turbine in Yawed Condition," JSME International Journal Series B, Vol. 48, No. 1, 2005, pp. 156-163.

[3] T. H. H. Carolus and M. Stremel, "Blade Surface Pressure

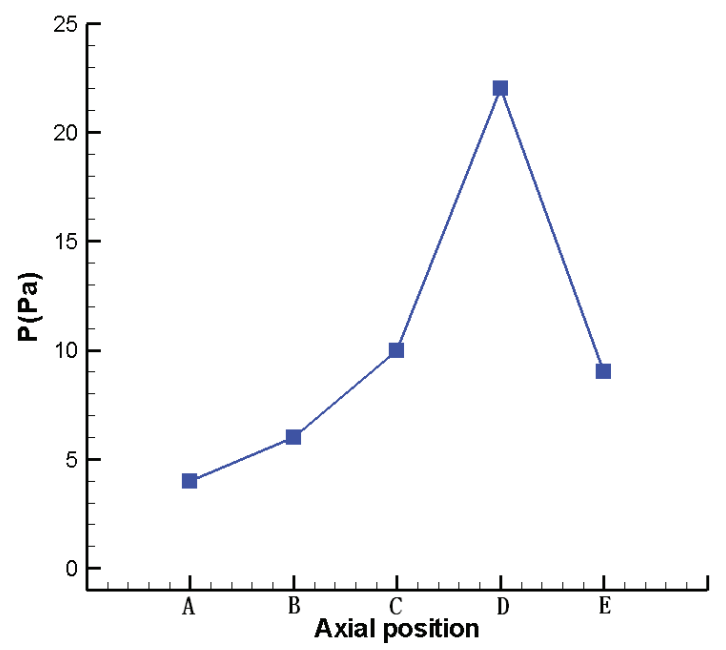

Figure 23. The peak values of the first order spectral.

Fluctuations and Acoustic Radiation from an Axial Fan Rotor Due to Turbulent," Acta Acustica united with Acustica, Vol. 88, No. 4, 2002, pp. 472-482.

[4] C. H. Sieverding, T. Arts, R. Denos and J. F. Brouckaert, "Measurement Techniques for Unsteady Flows in Turbomachines," Experiments in Fluids, Vol. 28, No. 4, 2000, pp. 285-321.

[5] R. W. Ainsworth, R. J. Miller, R. W. Moss and S. J. Thorpe, "Unsteady Pressure Measurement," Measurement Science \& Technology, Vol. 11, No. 7, 2000, pp. 1055-1076.

[6] S. B. Yang, G. S. Song, J. Lin and K. M. Chen, "The Design of an Opti-Eletronic Pressure Measuring System for the Measurement of the Internal Flow Field in a Rotating Fan," Journal of East China University of Technology, Vol. 19, No. 2, 1997, pp. 41-51. 